\title{
A violência na mídia como tema da área da saúde pública: revisão da literatura
}

\author{
Violence in the media as subject \\ in the public health area: revision of literature
}

Kathie Njaine 1

Maria Cecília de Souza Minayo 1

\footnotetext{
1 Centro-Latino Americano de Estudos de Violência e Saúde Jorge Careli, Escola Nacional de Saúde Pública, Fiocruz. Av. Brasil 4.036, Manguinhos, 21040-361, Rio de Janeiro RJ. kathie@claves.fiocruz.br
}

\begin{abstract}
This article aims to study the main scientific, international and national contributions produced in health area, on subject "violence in the media and its effect on children and adolescents". Through the international and national bibliographical databases of health area, had been accessed the scientific production, in its great majority from the United States, review articles, protocols and documents produced which had synthesized the conclusions of these studies. It is also considered the scarcity of Brazilian research on violence in the media at the health side and also the necessity to adjust theories and methods to the national context. It is also stressed the importance to investigate violence in the media under the optics of public health in order to contribute to violence prevention and preserve children and adolescents health.
\end{abstract}

Key words Violence, Media, Adolescent, Public health
Resumo O artigo tem como objetivo estudar as principais contribuições científicas, internacionais e nacionais, produzidas pela área da saúde sobre o tema violência na mídia e seus efeitos sobre crianças e adolescentes. As pesquisas sobre a produção científica, em sua grande maioria originária dos Estados Unidos, artigos de revisão, protocolos e documentos produzidos que sintetizaram as conclusões desses estudos foram feitas nas bases de dados bibliográficos internacional e nacional da área da saúde. Discute-se a escassez de pesquisas brasileiras sobre a violência na mídia do ponto de vista da saúde e a necessidade de adequar teorias e métodos ao contexto nacional. Destaca-se também a importância de investigar a violência na mídia sob a ótica da saúde pública a fim de contribuir para a prevenção da violência e para a promoção da saúde de crianças e adolescentes.

Palavras-chave Violência, Mídia, Adolescente, Saúde pública 


\section{Introdução}

Neste artigo busca-se apontar as principais contribuições das pesquisas sobre violência na mídia e seu impacto na infância e adolescência, identificadas na literatura internacional e nacional do campo da saúde. No âmbito internacional, a produção científica se concentra principalmente nas áreas da medicina, psicologia e pediatria; e no nacional, há uma maior contribuição da área da psicologia, embora ainda bastante escassa se comparada à internacional. Do ponto de vista da saúde pública no Brasil, os trabalhos são quase inexistentes, fazendo-se necessário sério investimento na busca de uma compreensão cultural específica voltada, primordialmente, para a prevenção da violência e para a promoção da saúde de crianças e adolescentes.

O Programa do Adolescente da Organização Pan-Americana da Saúde (OPAS/OMS) vem apontando a questão da violência na mídia como uma das prioridades de investigação, diagnóstico e prevenção a ser tratada pelo setor de saúde juvenil nas Américas (McAlister, 2000). De um lado, essa preocupação é justificada pela grande circulação de produtos midiáticos violentos, distribuídos, sobretudo, pelos Estados Unidos aos demais países do continente e para grande parte do mundo. Pesquisadores europeus e também norte-americanos vêm demonstrando que os programas produzidos nos EUA e exportados contêm mais quantidade e intensidade de violência que os de origem dos próprios países. Por outro lado, os estudiosos alertam que, com o fluxo global de informação pelas várias mídias (videogames, internet etc.), tornou-se muito mais difícil, para as sociedades, controlar a qualidade dos conteúdos em circulação.

Além do mais, em sendo a violência uma produção histórico-social, são necessários investimentos constantes na interpretação das novas formas de sua apresentação e de suas intrincadas articulações. Tal é o caso da necessidade de compreensão dos tipos específicos de violência próprios desse momento de mudanças profundas nos modos, meios e fatores de produção, circulação e consumo, sob a égide da revolução microeletrônica e de todos os meios comunicacionais e informacionais. Nesse sentido, a OPAS enfatiza a necessidade de se aplicarem modelos de investigação que contemplem os aspectos socioeconômicos e culturais de cada país. A busca de conhecimentos mais específicos permite elaborar políticas e estratégias adequadas a uma intervenção dos atores da saúde pública.

\section{O estágio de desenvolvimento das pesquisas no âmbito internacional}

Desde a década de 1960 alguns países da América do Norte, Europa e Ásia vêm investigando os efeitos da violência na televisão, sobretudo relacionada ao público infantil. Atualmente nota-se um investimento em pesquisas sobre a temática violência na mídia em diversas regiões do mundo, uma vez que os meios de comunicação tornaram-se inquestionavelmente um fenômeno de massa, difundindo visões de mundo, valores e imagens em escala global e com tecnologias cada vez mais avançadas. Essas pesquisas, entretanto, estão distribuídas desigualmente e a grande maioria está concentrada nos países da América do Norte.

Somente nos Estados Unidos foram realizados e revistos mais de 1.000 estudos no campo da saúde nas últimas décadas (Strasburger, 1993). Esses trabalhos surgiram a partir da preocupação de profissionais de saúde diante da crescente exibição de cenas violentas nos programas de televisão, paralelamente à constatação de um aumento do comportamento agressivo em crianças e adolescentes. Estudos conduzidos em laboratório procuravam avaliar o comportamento de crianças durante a exposição a programas violentos. Observando o comportamento de crianças em comunidades que possuíam televisão e comparando-o ao de outras que viviam em comunidades sem esse meio de comunicação, dois estudos realizados na Austrália e na Colúmbia Britânica, no início da década de 1970, obtiveram resultados sobre uma mudança no comportamento das crianças que conviviam com a presença da televisão. Essas apresentavam uma conduta mais agressiva e menos criativa nas brincadeiras em relação às que viviam em comunidades sem a presença da TV. A realização desses estudos foi considerada inviável no mundo ocidental atual pela dificuldade de se encontrar grupos para comparar e controlar as diferentes variáveis estudadas.

Um método comum utilizado por pesquisadores de todo o mundo tem sido o de pesquisas de opinião por amostragem. Mas esse tipo de abordagem também é considerado insuficiente por não esclarecer se a televisão tem influência sobre o comportamento de grupos etá- 
rios mais jovens. Esses enfoques citados anteriormente têm sido atualmente bastante criticados por pesquisadores de diversos países, no sentido de que procuram estabelecer uma relação direta de causa e efeito da violência na mídia com o comportamento de crianças e adolescentes. Contudo, a maioria dos estudos admite que os meios de comunicação são uma importante fonte auto-relatada de informações sobre sexo, drogas e violência para esse grupo etário.

A análise de conteúdo tem sido considerada um dos métodos que mais tem contribuído para as pesquisas sobre a mídia por quantificar cenas de violência na programação; identificar imagens estereotipadas de grupos sociais específicos; e demonstrar o quanto a indústria cultural tem sido mantida imutável diante das preocupações tanto dos profissionais de saúde quanto da educação. No entanto, tais análises não contemplam o aspecto da recepção desses conteúdos e a influência ou não dessas cenas sobre a vida de crianças e adolescentes.

Três modelos teóricos vêm sendo utilizados com mais freqüência para investigar a questão da violência na mídia e o seu impacto sobre a saúde de crianças e adolescentes: um está centrado na teoria da aprendizagem social; o segundo enfoca a teoria dos efeitos preparatórios; e o terceiro é denominado modelo de script.

A teoria da aprendizagem social, elaborada por Albert Bandura (1965) na década de 1960, demonstra que as crianças, em especial, imitam o que vêem na tela ou incorporam padrões de comportamento por ela propostos. Pesquisas de campo mostraram que a agressão é aprendida em idades menores e à medida que a criança cresce, as mudanças se tornam mais difíceis.

A teoria dos efeitos preparatórios (Berkowitz, 1984), com base na teoria da aprendizagem social, enfatiza o papel das características pessoais dos espectadores e relata que muitos dos efeitos decorrentes da exposição à violência na mídia ocorrem de forma transitória. Por exemplo, alguns espectadores frustrados e com raiva em seu ambiente real estariam mais suscetíveis a assistir cenas de violência na televisão e a terem uma conduta mais agressiva na vida real.

A teoria do script (Huesmann, 1986) constitui um modelo de desenvolvimento social dos efeitos da violência e tem base nas abordagens da cognição social, segundo as quais, o comportamento social é controlado por scripts ofe- recidos durante a infância. Esses scripts ficam programados na memória e são usados ao longo da vida como guias para o comportamento social e para a resolução de problemas. Em outras palavras, a exposição precoce à violência na TV, segundo os estudos longitudinais desse autor, está associada a comportamentos agressivos futuros. Wartella et al. (1999) apontam a importância dessa teoria por demonstrar elementos-chave para configurar o impacto da violência na mídia sobre as crianças: o estágio de realização intelectual do espectador; a popularidade social do personagem; a identificação com os personagens da TV; a convicção no realismo da violência na TV; e o grau de fantasia do espectador sobre agressão.

Alguns estudos observam que nem todo modo de representação da violência e nem toda a reação do público devem ser analisados da mesma forma, ressaltando a necessidade de distinguir fatores que estão relacionados ao contexto da representação e às características individuais do espectador. Diversos fatores referentes à natureza da representação que podem aumentar ou minimizar o risco dos efeitos nocivos da violência na televisão foram identificados: características do perpetrador da violência; características da vítima; motivo para a violência do agressor; presença de armas; duração e a intensidade das cenas violentas; grau de realismo das cenas de agressão; violência recompensada ou punida; danos morais, físicos e emocionais que esses atos provocam; existência de humor na apresentação das cenas de violência. A capacidade cognitiva das crianças é considerada um fator de vulnerabilidade a determinadas formas de representação da violência, principalmente as menores de sete anos, por não distinguirem claramente a violência dos desenhos animados da realidade (National Television Violence Study, 1998).

Uma outra conseqüência apontada na literatura, decorrente da exposição a longo prazo à violência na tela, é a dessensibilização. Esse efeito se caracteriza pela indiferença dos indivíduos quando a violência é dirigida a outros e há atitude de omissão em relação à vítima. Outro fenômeno estudado é o da intensificação do medo, por parte dos espectadores, de serem vítimas da violência na vida real (Gerbner et al., 1986). Esse aspecto do medo foi observado nas pessoas expostas a muitos episódios de agressão na TV. Expressa-se por meio de atitudes autoprotetoras e nas formas desconfiadas de se relacionarem com os outros. Os autores expli- 
cam que tais espectadores tendem a igualar a violência na tela, incluindo a que é veiculada nos telejornais, com a violência na vida real.

Mais recentemente, os estudos culturais têm contribuído para uma interpretação do fenômeno da comunicação em diferentes contextos socioculturais. Na América Latina, os trabalhos de Martín-Barbero (2001), Canclini (1999) e Ortiz (1994) dentre outros oferecem um referencial teórico importante para uma compreensão cultural sobre as formas de interpretação e recepção do discurso da mídia no cotidiano.

Dados recentes demonstram a importância de trabalhar esse tema da relação violência e mídia no processo educativo e na saúde. Mas, apesar de décadas de pesquisas que evidenciam os riscos da violência na mídia, associados a outros, para o crescimento e desenvolvimento de crianças e adolescentes, a televisão norteamericana mantém um nível alto e freqüente de violência na tela. Strasburger e Donnerstein (1999) apontam a ausência de programas nas escolas norte-americanas para refletir sobre os conteúdos violentos nos meios de comunicação e trabalhar a prevenção da violência. Ao contrário, países como o Canadá, Austrália, Inglaterra, Escócia e África do Sul vêm implementando diversos projetos para crianças, alguns iniciados a partir do jardim da infância.

As análises da produção científica de quatro décadas e os protocolos divulgados pelas principais instituições de saúde, sobretudo norte-americanas, atestam que a violência na mídia constitui um problemas de saúde pública.

Um dos trabalhos pioneiros, elaborado nos Estados Unidos pelo Surgeon General's Scientific Advisory Committee on Television and Social Behavior, em 1972, reuniu 23 projetos de pesquisas em diversas universidades e institutos, com o objetivo de analisar o conteúdo da programação televisiva e apontar os possíveis impactos da violência sobre os valores e comportamentos dos espectadores. Algumas das preocupações desses profissionais se relacionavam à forma como as vítimas dos conflitos raciais e dos conflitos de guerra eram representadas. Tais pesquisas destacaram a importância de uma melhor compreensão do impacto social e psicológico da violência sobre as crianças e a necessidade de uma abordagem clara e compreensiva da violência veiculada pela televisão.

Em 1993, a Associação Norte-Americana de Psicologia divulgou o relatório Juventude e vio- lência, enumerando alguns dos principais fatores socioculturais relacionados a essa questão e destacou a importância da intervenção e da prevenção da violência na mídia, por parte dos profissionais de educação e saúde. A partir de um complexo retrato da juventude norte-americana, incluindo aí os nativos, os afro-americanos, os asiáticos e os latino-americanos, o documento apontou a violência na mídia como um dos fatores responsáveis pelo incremento da violência na sociedade, tanto no que se refere à perpetração de atos que afetam a integridade do outro, quanto à vitimização desse grupo etário. Em síntese, o relatório destacou que, ao longo do tempo, a incorporação de hábitos agressivos em tenras idades serve como base para comportamentos agressivos futuros e concluiu que a exposição excessiva à violência na televisão pode: a) contribuir com atitudes violentas contra mulheres (quando as representam em papéis de vítima) e contra minorias étnicas (quando as representam como grupos agressivos); b) impulsionar os jovens para atitudes consumistas, fazendo uso da violência para obter produtos que a propaganda apresenta.

No Canadá, o National Clearinghouse on Family Violence divulgou, em 1994, um documento sobre os efeitos da violência na mídia sobre as crianças, enfatizando o papel dos pais na mediação da relação televisão e público infantil. Algumas das recomendações desse documento são: a criação de rotinas, nas quais as crianças devem realizar outras atividades, limitando o tempo diante da TV; a adequação de uma abordagem sobre a convivência com a TV à idade da criança e o diálogo sobre os valores positivos para um ambiente não agressivo.

A publicação Guia Médico para Orientação sobre a Violência na Mídia (1996), da Associação Médica Americana, alerta os profissionais de saúde sobre os possíveis efeitos causados pela excessiva exposição à violência na televisão e ao consumo desse meio (Quadro 1).

Em recente publicação, a Academia Americana de Pediatria recomenda uma série de medidas a serem tomadas por profissionais de saúde, pais, escola, comunidade, governo e meios de comunicação de forma a intervir nos níveis de violência na televisão, nos videogames, nos filmes, na mídia impressa e nos clipes musicais. Essa entidade recomenda sobretudo a parceria dos pediatras com profissionais de demais entidades de diversas áreas para a elaboração de uma agenda da saúde pública com 
Quadro 1

Efeitos potenciais adversos para a saúde e conseqüências sociais do excesso de atividades na mídia

Aumento do comportamento violento

Obesidade

Diminuição de atividades físicas e aptidões

Aumento dos níveis de colesterol

Excesso de consumo de sódio

Esforço repetido para insultar ou ferir em jogos de computador

Insônia

Ataque fótico em indivíduos vulneráveis

Prejuízo no desempenho escolar

Aumento do uso de tabaco e álcool

Aumento da atividade sexual

Diminuição do grau de atenção

Diminuição da comunicação familiar

Foco excessivo no consumo

Fonte: American Medical Association. Physician Guide to Media Violence, Chicago, 1996.

relação à violência na mídia (American Academy of Pediatrics, 2001).

No Japão, desde a década de 1960, a questão da violência na mídia vem preocupando tanto a área da saúde quanto a da educação, no que se relaciona principalmente à audiência infantil. A maioria dos estudos japoneses também estabelece uma relação causal entre o ato de ver violência na TV e o comportamento agressivo, mas destaca a importância do ambiente familiar e das características da criança como fatores que influenciam nessa relação. Revisando a literatura japonesa sobre o tema, Koidara (1999) destaca que, a partir da segunda metade da década de 1970, as análises de conteúdo contribuíram para categorizar as cenas dos desenhos animados e apontar as diferenças na forma como a violência é representada na programação infantil japonesa em relação à TV norte-americana. Os resultados dessas pesquisas demonstram que, ainda que a quantidade de cenas de agressão seja similar às da programação norte-americana, a natureza da violência representada na TV japonesa é mais realista. Uma pesquisa em oito países da Ásia, incluindo o Japão, sobre a programação infantil, mostrou as principais diferenças em relação à programação ocidental: nos países asiáticos os conflitos interpessoais e intrafamiliares são mais ressaltados; há uma ênfase maior no sofrimento das vítimas; em geral, os heróis sofrem mais que os vilões; e a violência na TV é mais explicitada, como as imagens de sangue nas agressões físicas.
Desde a década de 1970, a Austrália e a Nova Zelândia também vêm realizando pesquisas sobre a violência na mídia, tanto do ponto de vista da produção quanto da recepção. Durkin e Low (1999) revisaram esses estudos e identificaram pesquisas que demonstram os efeitos nocivos da propaganda de brinquedos anti-sociais; estudos sobre jogos de computador; e as tradicionais investigações que analisam a associação da mídia com os níveis de agressividade em crianças. Os autores consideram que a abordagem desses temas é ainda muito incipiente, e que pesquisas sobre a percepção de crianças, adolescentes e pais sobre as formas físicas e simbólicas da agressão, representadas na televisão, são mais esclarecedoras. Esses autores afirmam que não há um consenso entre os pesquisadores de seus países quanto aos efeitos nocivos da violência na mídia e o desenvolvimento de crianças e adolescentes. O que existe é uma crescente preocupação com essa questão. A Academia Australiana de Pediatria, no entanto, publicou um documento em 1994, declarando que a simples quantidade de horas assistindo à televisão, sobretudo no caso de programação violenta, já indica que esse meio pode influenciar de forma nociva o desenvolvimento infantil. O tempo gasto diante da televisão e com outras mídias tem servido de dado para pesquisas, sobretudo em países com alto consumo de produtos midiáticos apresentando episódios e cenas de violência na programação. Estudo recente afirma que as crianças e jovens norte-americanos entre dois e 18 anos despen- 
dem em torno de seis horas e meia em ambientes multimídias (televisão, filmes, videogames, impressos, rádio, computador e internet). Esse tempo é muito maior do que é utilizado com qualquer outra atividade, com exceção de dormir (The Henry J. Kaiser Family Foundation apud American Academy of Pediatrics, 2001).

Estudos europeus sobre a violência na mídia, em especial, na televisão, se concentram, em maioria, na década de 1990. No Reino Unido, Alemanha, França, Dinamarca, Bélgica, Espanha, Finlândia, Suécia, Holanda e Irlanda as pesquisas sobre criança e mídia partem, sobretudo, das áreas de sociologia, jornalismo e psicologia. Contudo, diferente do que acontece nos EUA, a principal teoria que ancora os estudos tem sido a da recepção, seguida pelas mais tradicionais como a de efeitos e a de usos e gratificações. Os métodos mais utilizados têm sido as revisões da literatura, entrevistas com grupos e uso da observação participante (Linné, 1999).

Para importante parcela de pesquisadores europeus muitas pesquisas norte-americanas deram atenção exagerada às relações estritamente causais do ato de assistir a cenas de violência na mídia. Esses estudiosos consideram que tais efeitos são muito difíceis de serem demonstrados. Outra crítica aos resultados das investigações norte-americanas, realizada por investigadores europeus, é que elas não esclarecem a magnitude do impacto da violência na mídia em relação a outros fatores provenientes da violência na sociedade (Von Feilitzen, 1999).

Em 1998, uma investigação multifocal, realizada em 23 países, inclusive no Brasil, envolvendo 5.000 crianças de 12 anos de idade, procurou entender, através de aplicação de questionários, como esse grupo etário percebe a violência na tela. $\mathrm{O}$ estudo mostrou que a televisão é uma mídia presente em todas as regiões pesquisadas. E que as crianças passam mais tempo em frente da TV (uma média de 3 horas/dia) do que utilizando outro meio de comunicação (rádio ou livros), ou realizando qualquer outra atividade, inclusive seus deveres escolares. Essa pesquisa enfatizou o fascínio que a violência exerce sobre as crianças e o modo como relacionam a recompensa dos heróis da tela às suas condutas na vida real, sugerindo que a televisão pode servir de modelo para esse grupo. No entanto, os autores do estudo ressaltaram o que já vinha sendo alertado por outros analistas: é preciso investigar e compreender a intervenção de outros fatores como a relação entre a mensagem e a personalidade da criança, seu ambiente real, sua experiência com agressão, suas circunstâncias familiares e o contexto cultural de sua existência (Groebel, 1999).

Em alguns outros países tem havido investimento de pesquisa sobre o tema aqui concernente, ainda que, em escala bem menor e de forma menos sistemática que nos países da Comunidade Européia e nos Estados Unidos. Tal é o caso, por exemplo, de investigações realizadas em Israel, China e África do Sul que, dado o grau de desenvolvimento dos trabalhos, acrescentam pouco às teorias e modelos aqui já descritos.

\section{A situação das pesquisas na América Latina e Brasil}

Na América Latina e Brasil os estudos sobre a questão da violência na mídia, produzidos pelo campo da saúde, são escassos se comparados aos investimentos realizados na América do Norte, Europa e Ásia. A maioria dos pesquisadores concorda que não é possível generalizar, para os países latino-americanos, os resultados das pesquisas realizadas em outras partes do mundo. Cada sociedade possui aspectos socioculturais específicos que determinam o modo de produção, circulação e consumo dos produtos midiáticos, ainda que os processos tecnológicos e a realidade virtual transponham essas fronteiras.

Merlo-Flores (1999), investigando a questão na Argentina na década de 1980, pesquisou uma amostra de duas mil crianças em áreas urbanas e constatou que elas se relacionam umas com as outras utilizando elementos da televisão, e que um desses elementos mais freqüentes é a agressão. Para essa autora, a agressão se tornou um novo "código de comunicação", sobretudo para as pessoas mais jovens. No entanto, a própria investigadora questiona se esse fator torna as crianças necessariamente agressivas no sentido patológico.

A televisão comercial tem sido a mídia mais utilizada por crianças e adolescentes do Brasil. Apesar de apresentar uma qualidade de programação bastante questionada por pais e professores, pesquisa recente do Unicef, que ouviu 5.280 adolescentes em todo o Brasil, revela que $52 \%$ desse grupo etário têm na televisão a maior fonte de lazer. Cerca de 70\% consideram 
a programação da TV “muito boa” (Unicef/Fator OM, 2002). Enfatizar os aspectos positivos da mídia, assim como o compromisso de uma parte dos profissionais da área de comunicação com a qualidade da programação, tem sido um esforço de âmbito mundial, também praticado no Brasil.

A produção científica brasileira do campo da saúde, sobre o tema violência na mídia, é pequena. Destaca-se maior contribuição da área da psicologia, apesar dessa não ser contínua e representativa em termos nacionais, concentrando-se entre as décadas de 1970 e 1980. As investigações enfocam principalmente a programação preferida do público infanto-juvenil e a relação que porventura tenha com comportamentos agressivos.

Beraldi (1978) examinou a preferência de crianças pré-escolares na faixa etária de quatro a seis anos de idade e encontrou que a grande maioria desse grupo escolhia os desenhos animados. Dos dez personagens mais populares, oito foram considerados violentos e o Pica-Pau foi o personagem favorito. O Pica-Pau também foi apontado como o personagem mais popular em outros trabalhos com crianças escolares (Pacheco, 1981; Resende e Fusari, 1982).

Revisando esses trabalhos anteriores, Andersen (1986) encontrou que vários aspectos negativos do personagem Pica-Pau indicados nessas investigações coincidiam, como a agressividade, os métodos pouco escrupulosos que esse personagem utiliza para atingir seus objetivos e a forma dominadora e sarcástica com que se relaciona com outros personagens secundários. Alguns aspectos divergentes demonstraram a ambigüidade do personagem, avaliado por uns como desonesto e desagradável e por outros, como indefinido. Pesquisa na área da educação identificou que a popularidade do Pica-Pau entre as crianças está relacionada à sua maneira humorada, esperta e engraçada de viver e conseguir seus objetivos a qualquer custo (Fischer, 1982). Entretanto, o conteúdo violento do desenho ainda preocupa uma parcela dos profissionais da área da saúde.

Em sua pesquisa, Andersen (1986) procurou categorizar a violência veiculada nos desenhos e verificou que o tema básico desse gênero é a perseguição e a agressão física que, geralmente, não causam danos reais e os personagens principais se saem bem. Essa autora observou ainda que os principais personagens dos desenhos e também os secundários são figuras humanas ou animais masculinos e adultos, do- tados de superpoderes, o que pode fornecer modelos de identificação para crianças do sexo masculino.

Kasprzak (1997) também analisou os conteúdos violentos presentes em um episódio da série Cavaleiros do zodíaco. Buscou associá-los à construção de valores sócio-morais em crianças pré-escolares e identificou aspectos como a polarização de uma moral do "bem" e do "mal", a banalização da violência e o uso do poder associado a ela. Observou que algumas brincadeiras infantis faziam referência aos personagens dos desenhos, incorporando atitudes agressivas, a partir da cultura televisiva.

Algumas pesquisas da área da educação (Fischer, 2001) e comunicação (Rangel, 1996) têm contribuído para uma melhor compreensão da interação televisão-receptor, a primeira voltada para o público infantil e a segunda para o adolescente.

As análises sobre a relação televisão-adolescente, entretanto, ainda são escassas. O trabalho de Coutinho (1972), considerado pioneiro na temática no país, demonstrou a importância desse meio para a vida do adolescente brasileiro. Witter (1991) estudou a preferência de jovens na programação televisiva e verificou que os prediletos dos estudantes, entre 14 e 17 anos, eram a telenovela, o telejornal e o filme, respectivamente. Encontrou também que os adolescentes, em geral, gastam uma média de três horas diárias na frente da TV, mas os de estratos econômicos mais baixos despendem mais tempo nessa forma de lazer. Apesar disso, os entrevistados declararam que a televisão influencia muito pouco o seu comportamento. Pesquisas posteriores também verificaram que os adolescentes não se consideram influenciáveis pela mídia (Minayo et al., 1999).

Existe ainda uma ausência de estudos que mostrem como o adolescente é retratado na televisão e em outras mídias. Alguns são precursores como o de Guerra (1995) que analisou o tratamento dado pelos jornais de São Paulo à questão da violência física cometida no âmbito familiar. A autora verificou que a imprensa dedica pouco espaço aos eventos de vitimização, exceto em casos graves ou, pode-se dizer "bárbaros”, sugerindo mais a criminalização do agressor do que a proteção à vítima. Essa pesquisa também constatou algumas questões importantes: a) a imprensa reforça o ciclo de silêncio que cerca esses eventos, quando não noticia os denunciantes da agressão e nem enfatiza a participação de qualquer cidadão na de- 
núncia; b) protege a instituição familiar em que ocorre a violência, atribuindo os acontecimentos a uma conduta particular de um pai ou uma mãe, distorcendo a responsabilidade política dos governos no tratamento da violência doméstica; c) e por fim, tem um discurso moralizante, superficial e alienado com relação a esse tema.

Alguns outros estudos vêm demonstrando uma estigmatização subliminar pela mídia contra jovens na veiculação de notícias sobre violência. A percepção social da delinqüência aumenta na medida em que a mídia destaca determinados grupos sociais e espaços, influenciando na formulação de políticas para os jovens como o rebaixamento da idade penal, e na perpetuação do estereótipo do "marginal", "pivete" e "menor" (Noronha, 2000; Menin, 2000; Njaine \& Minayo, 2002).

Do ponto de vista do uso da imagem da juventude para fins comerciais, Pinsky (1994) analisou a propaganda de bebidas alcoólicas na televisão brasileira e observou que: a) o público-alvo desses comerciais é freqüentemente o jovem; b) a propaganda de álcool enfatiza muitas vezes o efeito ansiolítico e relaxante do produto; c) as mensagens de bebidas, como a cerveja, estão relacionadas à identidade nacional ou grupal; d) as mensagens sobre o abuso de bebidas alcoólicas foram detectadas em 7,2\% da amostra. A autora chama a atenção para a naturalização da venda e do consumo de bebida alcoólica na sociedade e a necessidade de refletir sobre a aceitação naturalizada desse hábito, reforçado pela propaganda veiculada na mídia.

Gorgulho (2001) enfocou aspectos do conteúdo das notícias da imprensa escrita sobre o uso de drogas e a questão da saúde e verificou que a maioria das matérias publicadas em 2000 (979 artigos) aborda o tema da repressão; e 422 artigos, a atuação da polícia na apreensão de drogas. Somente $7 \%$ das matérias trata de temas relacionados à saúde. E a prevenção foi abordada em somente $4,36 \%$ das matérias. Os resultados dessa pesquisa, realizada no âmbito do Centro Brasileiro de Informações sobre Drogas (CEBRID), demonstram que: a) o álcool e o tabaco são raramente tratados pela mídia como drogas socialmente difundidas; b) há pouca ênfase na atuação de redução de danos, prática inovadora de saúde no país; c) é recorrente uma visão moralista e criminalizadora, associando o uso de drogas à violência. A atuação da mídia contribui para a marginalização do usuário de droga, o que acaba por contrariar o trabalho de muitos profissionais da saúde que atuam nessa área e que buscam uma relação de respeito com cada indivíduo. A discriminação do usuário de droga também passa pela focalização da mídia nos indivíduos negros e pobres, ocultando o nível de envolvimento da classe média branca, revela essa pesquisa.

Minayo e colaboradores (1999) investigaram a opinião de jovens estudantes cariocas, de 14 a 20 anos de idade, sobre as questões da juventude, violência e cidadania no município do Rio de Janeiro. Os meios de comunicação foram abordados por sua importância no cotidiano da juventude, o que ficou comprovado na pesquisa quantitativa, quando indicaram o quarto lugar para a mídia, dentre as instituições em que mais confiam. Nessa pesquisa, realizada entre 1998 e 1999, foram entrevistados 1.220 jovens nos domicílios e em escolas públicas e privadas e 443 educadores. Jovens de todos os estratos sociais criticaram a imagem que a mídia apresenta da juventude carioca, associando-a a drogas, sexo e baderna. Os dos estratos sociais mais baixos consideram que a juventude pobre é a mais focalizada e associada à violência pelos meios de comunicação social. $\mathrm{Na}$ opinião dos estudantes, a mídia influencia no aumento dos conflitos sociais porque distorce os fatos, os espetaculariza e estimula o consumismo exacerbado.

Alguns trabalhos da área de pediatria, nutrição e psicologia demonstram uma preocupação com a influência do ambiente multimídia sobre crianças e adolescentes, no que se refere: ao papel que as cenas eróticas exerce sobre a sexualidade (Pinto, 1995); aos discursos da dieta refletidos na imagem corporal (Serra, 2001); e aos conteúdos agressivos no comportamento de risco para a violência (Feijó e Oliveira, 2001). A Sociedade Brasileira de Pediatria divulgou em 2001 o documento Promoção de Segurança da Criança e do Adolescente frente à Mídia (TV, Internet). Nesse texto, recomenda aos pais que estejam atentos em relação aos hábitos de seus filhos de assistir TV e usar a internet, buscando limitar o tempo na frente desses meios, estimular outras atividades de lazer, conhecer os programas a que os filhos assistem $\mathrm{e}$ ajudar a compreender o conteúdo que é veiculado (Doria Filho, 2001).

Reato (2001) e Yunes (2001) destacam que, do ponto da vista da saúde pública e da epidemiologia, a programação violenta nos meios de 
comunicação é considerada um fator de risco. Esses pesquisadores propõem a mediação de pais, profissionais de saúde e educação nesse binômio televisão-adolescente, para promover orientação e prevenção.

\section{Algumas reflexões para os estudos no campo da violência e saúde}

A proposta central da saúde pública, ainda que seja difícil defini-la sob a ótica positivista, é a qualidade da vida. E interessam ao campo da saúde todos os dispositivos sociais que possam contribuir para melhorar a existência individual e coletiva. Na infância e na adolescência, esses dispositivos devem ser lidos pelo viés do crescimento e do desenvolvimento. Portanto, não cabe ao setor demonizar nada daquilo que constitui elemento do modus vivendi dos jovens, no atual estágio de avanço tecnológico e social. A convivência com as várias mídias faz parte do cotidiano desse grupo socioetário. É importante assinalar que a televisão, a mídia de mais amplo acesso, não pode ser vista somente como um veículo de comunicação, mas como um produtor de sentidos e construtor de valores. Os valores que circulam na mídia são, portanto, expressões de sentido dadas tanto pelo produtor quanto pelo receptor da mensagem, e ocupam o mesmo espaço (Sousa, 1995). E é nesses espaços, que atravessam a experiência cotidiana dos adolescentes e jovens, com os mais diferentes níveis de violência real ou simbólica, que o setor saúde também atua. Essa atuação não se restringe, no entanto, somente à identificação de uma relação de causa e efeito da violência na mídia sobre o comportamento dos grupos. No entanto, ela deve ser exercida, também, no aprofundamento de conhecimentos sobre que outras conseqüências o discurso sobre a violência é capaz de gerar, independente, inclusive, da intenção de quem o produz. Como reflete Groebel (1999), além da agressão "funcional", os homens desenvolveram a agressão "destrutiva", o genocídio, a tortura hedonística, a humilhação, que não podem ser explicados em termos de sobrevivência. São esses que, em geral, estão amplamente distribuídos na mídia. As imagens estereotipadas de grupos sociais como mulheres, homossexuais, negros são abusadamente utilizadas pela mídia e se constituem em uma forma de violência pouco reconhecida pela sociedade e por vezes é motivo de diversão e sarcasmo. Mas é importante também lembrar que os níveis de violência na vida real muitas vezes não são sempre reconhecidos e que a discriminação e o preconceito, por exemplo, não são atitudes exclusivas dos profissionais da mídia, estando presente também nas práticas dos profissionais da área da educação e da saúde que lidam com crianças e adolescentes refletindo negativamente na socialização desse grupo.

Constata-se, por fim, a necessidade do imprescindível diálogo das disciplinas e dos métodos para as pesquisas nesse campo da violência e saúde. No caso brasileiro, em relação à produção de conhecimentos se identifica uma grande lacuna tanto em relação a questões gerais como específicas. O próprio reconhecimento do assunto como problema do âmbito da saúde pública ainda precisa avançar. Para tal, se faz necessário investir em pesquisas qualitativas, epidemiológicas e estudos longitudinais em nível nacional, com ênfase nas peculiaridades culturais e nas formas de sociabilidade dos adolescentes e jovens brasileiros. 
American Academy of Pediatrics 2001. Media violence. Pediatrics 108(5):1222-1226.

American Medical Association 1996. Physician guide to media violence. American Medical Association, Chicago.

American Psychological Association 1993. Violence and youth: psychology's response. Summary Report of the American Psychological Association Commission on Violence and Youth, vol. 1. American Psychological Association, Washington.

Andersen MJB 1986. Violência nos desenhos animados exibidos pela televisão: uma ponderação necessária. Tese de doutorado. Instituto de Psicologia, Universidade de São Paulo, São Paulo.

Australian College of Pediatrics 1994. Policy statement: Children's television. Journal of Pediatrics \& Child Health 30:6-8.

Bandura A 1965. Influence of model's reinforcement contingencies on the acquisition of imitative responses. Journal of Personality and Social Psychology 1:589-595.

Beraldi MJ 1978. Televisão e desenho animado: o telespectador pré-escolar. Dissertação de mestrado. Instituto de Psicologia, Universidade de São Paulo, São Paulo.

Berkowitz L 1984. Some effects of thoughts on anti - and prosocial influences of media events: a cognitiveneoassociation analysis. Psychological Bulletin 95:410-427.

Canclini NG 1999. Consumidores e cidadãos: conflitos multiculturais da globalização. Editora UFRJ, Rio de Janeiro.

Coutinho LF 1972. Adolescente e televisão: estudo junto a adolescentes ginasianos da cidade de Londrina. Tese de doutorado. Instituto de Psicologia, Universidade de São Paulo, São Paulo.

Doria Filho U 2001. Promoção de segurança da criança e do adolescente frente à mídia (TV, Internet). Departamento Científico de Segurança da Criança e do Adolescente. Sociedade Brasileira de Pediatria, Rio de Janeiro.

Durkin K \& Low J 1999. A criança, mídia e agressão: situação da pesquisa na Austrália e Nova Zelândia, pp. 125-147. In U Carlsson \& C Von Feilitzen (orgs.). A criança e a violência na mídia. Ed. Cortez-Unesco, São Paulo-Brasília.

Feijó RB \& Oliveira EA 2001. Comportamento de risco na adolescência. Jornal de Pediatria 77(2):125-134.

Fischer RMB 1982. O mito na sala de jantar. Dissertação de mestrado. Fundação Getúlio Vargas, Rio de Janeiro.

Fischer RMB 2001. Televisão e educação: fruir e pensar a $T V$. Autêntica, Belo Horizonte.

Fundo das Nações para a Infância/Fator OM 2002. A voz dos adolescentes. Unicef, Brasília.

Gerbner G et al. 1986. Living with television: the dynamics of the cultivation process, pp. 17-41. In J Bryant \& D Zillmann (eds.). Media effects. Lawrence Erlbaum, Hillsdale.

Gorgulho M 2001. Estudo da influência da mídia na representação social do usuário de drogas ilícitas, para a construção de uma política oficial brasileira. Dissertação de mestrado. Instituto de Psicologia, Universidade de São Paulo, São Paulo.
Groebel J 1999. O estudo global da Unesco sobre violência na mídia, pp. 217-239. In U Carlsson \& C Von Feilitzen (orgs.). A criança e a violência na mídia. Ed. Cortez-Unesco, São Paulo-Brasília.

Guerra VNA 1995. Violência física doméstica contra crianças e adolescentes e a imprensa: do silêncio à comunicação. Tese de doutorado. Serviço Social, Pontifícia Universidade Católica de São Paulo, São Paulo.

Huesmann LR 1986. Psychological processes promoting the relation between exposure to media violence and aggressive behavior by the viewer. Journal of Social Issues 42:125-139.

Kasprzak RG 1997. Desenhos animados em tempo de violência: uma contribuição para pensar a construção de valores sócio-morais em crianças pré-escolares. Dissertação de mestrado. Instituto de Psicologia, Universidade Federal do Rio Grande do Sul, Porto Alegre.

Koidara SI 1999. Uma análise da pesquisa sobre violência na mídia no Japão, pp. 93-123. In U Carlsson \& C Von Feilitzen (orgs.). A criança e a violência na mídia. Ed. Cortez-Unesco, São Paulo-Brasília.

Linné O 1999. O que sabemos da pesquisa européia sobre violência na mídia?, pp. 167-185. In U Carlsson \& C Von Feilitzen (orgs.). A criança e a violência na mídia. Ed. Cortez-Unesco, São Paulo-Brasília.

Martín-Barbero J 2001. Dos meios às mediações: comunicação, cultura e hegemonia. Editora UFRJ, Rio de Janeiro.

McAlister A 2000. La violencia juvenil en las Américas: estudios innovadores de investigación, diagnóstico y prevención. OPAS, Washington.

Menin MSS 2000. Representações sociais de justiça em adolescentes infratores: discutindo novas possibilidades de pesquisa. Psicologia, Reflexão e Crítica 13 (1):59-71.

Merlo-Flores T 1999. Por que assistimos à violência na televisão?, pp. 187-215. In U Carlsson \& C Von Feilitzen (orgs.). A criança e a violência na mídia. Ed. Cortez-Unesco, São Paulo-Brasília.

Minayo MCS et al. 1999. Fala galera: juventude, violência e cidadania na cidade do Rio de Janeiro. Garamond, Rio de Janeiro.

National Clearinghouse on Family Violence 1994. The effects of media violence on children. Family Violence Prevention Division. Health Promotion and Programs Branch/Health Canada. Ottawa, Ontorio.

National Television Violence Study 1998, vol. 3, Sage Publications, Thousand Oaks.

Njaine K \& Minayo MCS 2002. Análise do discurso da imprensa sobre rebeliões de jovens infratores em regime de privação de liberdade. Ciência \& Saúde Coletiva 7:285-297.

Noronha CV 2000. Domínios do medo social: violência, crime e pobreza na Grande Salvador. Tese de doutorado. Instituto de Saúde Coletiva, Universidade Federal da Bahia, Salvador.

Ortiz R 1994. Mundialização e cultura. Ed. Brasiliense, São Paulo.

Pacheco ED 1981. O pica-pau: herói ou vilão? Representação social da criança e reprodução da ideologia dominante. Tese de doutorado. Instituto de Psicologia, Pontifícia Universidade Católica de São Paulo, São Paulo. 
Pinsky I 1994. Análise da propaganda de bebidas alcoólicas na televisão brasileira. Dissertação de mestrado. Instituto de Psicologia, Universidade de São Paulo, São Paulo.

Pinto LFM 1995. Televisão e educação sexual. Jornal de Pediatria 71(5):248-254.

Rangel JG 1996. Exposiçãa à violência na televisão e suas relaçães no contexto de variáveis psicológicas e sociodemográficas dos adolescentes. Dissertação de mestrado. Programa de Pós-Graduação da Faculdade de Comunicação Social, Instituto Metodista de Ensino Superior, São Bernardo do Campo.

Reato LFN 2001. Meios de comunicação, pp. 207-219. In MI Saito \& LEV Silva (orgs.). Adolescência: prevenção e risco. Editora Atheneu, São Paulo.

Resende e Fusari MF 1982. Pica-Pau - programação televisiva infantil: telespectador paulistano pré-escolar; práticas sociais de desinformação e deseducação em reciprocidade de efeitos. Dissertação de mestrado. Instituto de Psicologia, Universidade de São Paulo, São Paulo.

Serra GMA 2001. Saúde e nutrição na adolescência: o discurso sobre dietas na mídia. Dissertação de mestrado. Escola Nacional de Saúde Pública, Fundação Oswaldo Cruz, Rio de Janeiro.

Sousa MW 1995. Recepção e comunicação: a busca do sujeito, pp. 35. In MW Sousa (org.). Sujeito, o lado oculto do receptor. Ed. Brasiliense, São Paulo.
Strasburger VC \& Donnerstein E 1999. Children, adolescents, and the media: issues and solutions. Pediatrics 103(1):129-139.

Strasburger VC 1993. Adolescents and the media: five crucial issues. Adolescent Medicine: State of the Art Reviews 4:479-493.

Strasburger VC 1999. Os adolescentes e a mídia: impacto psicológico. Artes Médicas, Porto Alegre.

Surgeon General's Scientific Advisory Committee on Television and Social Behavior 1972. Television and growing up: the impact of televised violence. Report to the Surgeon General, United States Public Health Service, Government Printing Office, Washington.

Von Feilitzen C 1999. Introdução, pp. 49-60. In U Carlsson \& C Von Feilitzen (orgs.). A criança e a violência na mídia.. Ed. Cortez-Unesco, São Paulo-Brasília.

Wartella E, Olivares A \& Jennings N 1999. A criança e a violência na televisão nos EUA, pp. 61-70. In U Carlsson \& C Von Feilitzen (orgs.). A criança e a violência na mídia. Ed. Cortez-Unesco, São PauloBrasília.

Witter C 1991. A televisão e o adolescente: análise de conteúdo da programação preferida. Dissertação de mestrado. Instituto de Psicologia, Universidade de São Paulo, São Paulo.

Yunes J 2001. A epidemiologia da violência, pp. 145-165. In MC Oliveira (org.). Demografia da exclusão social. Editora da Unicamp, Campinas.

Artigo apresentado em 25/7/2003

Aprovado em 2/9/2003

Versão final apresentada em 22/9/2003 